\title{
Hyperpotassemia and Bradycardia in a Bedridden Elderly Woman with Selective Hypoaldosteronism Associated with Low Renin Activity
}

\author{
Mitsuo Inada, Keiko Iwasaki, Chihiro Imai and Satoshi Hashimoto
}

\begin{abstract}
A bedridden 85 -year-old woman had hyperpotassemia $(7.7 \mathrm{mEq} / \mathrm{L})$ and bradycardia $(30 / \mathrm{min})$. Endocrinologic findings revealed a decrease in the renin-aldosterone system and normal adrenoglucocorticoid function. The results were consistent with the abnormalities seen in selective hypoaldosteronism with low renin activity. In addition, 9 of 11 patients, selected randomly from 72 bedridden elderly patients with normal serum sodium and potassium levels in our hospital, had diminished plasma renin activity (PRA) and plasma aldosterone concentration (PAC). The present patient was prescribed nonsteroidal anti-inflammatory drug (NSAID). NSAID reduces renal potassium excretion through the inhibition of renal prostaglandin synthesis. Therefore, the use of NSAID in bedridden elderly patients might intensify the underlying asymptomatic hypoaldosteronism and cause life-threatening hyperpotassemia.
\end{abstract}

Key words: bedridden elderly patient, hyperpotassemia, selective hypoaldosteronism, low renin activity, NSAID

(Inter Med 49: 307-313, 2010)

(DOI: 10.2169/internalmedicine.49.2416)

\section{Introduction}

Selective hypoaldosteronism was defined as a deficiency of aldosterone secretion by the adrenal gland, associated with normal adrenoglucocorticoid function, and it is characterized by hyperpotassemia (1-4). Moreover, PRA is frequently decreased in these patients $(3,4)$.

In the present paper, an 85-year-old bedridden woman had hyporeninemic hypoaldosteronism accompanied by normal serum cortisol level, and her serum potassium level was markedly elevated. Moreover, hyporeninemic hypoaldosteronism was also observed in 9 of 11 patients, selected randomly from 72 bedridden elderly patients with normal serum sodium and potassium values in our hospital, suggesting that asymptomatic hypoaldosteronism with low renin activity is not infrequent in bedridden elderly patients.

The present patient with hyperpotassemia was prescribed nonsteroidal anti-inflammatory drug (NSAID) for approximately 6 months. As is well known, NSAID impairs renal prostaglandin synthesis by the inhibition of cyclooxygenase activity $(5,6)$, and, therefore, the administration of NSAID might impair potassium homeostasis causing hyperpotassemia. It was initially described by Tan and co-workers (7) that long-term indomethacin therapy leads to further impairment in renal potassium excretion producing frank hyperpotassemia, particularly in the presence of underlying risk factors for hyperpotassemia such as renal disease. In addition, preexisting asymptomatic hyporeninemic hypoaldosteronism might increase the risk of NSAID-associated hyperpotassemia (8).

In the present paper, the clinical abnormalities, observed in the present patient, were investigated in relation to asymptomatic hyporeninemic hypoaldosteronism frequently seen in bedridden elderly patients.

\section{Case Report}

An 85-year-old woman was admitted to our hospital, because she required care for activities of daily living (ADL) 
Table 1. Results of Blood Chemistry and Peripheral Blood Counts

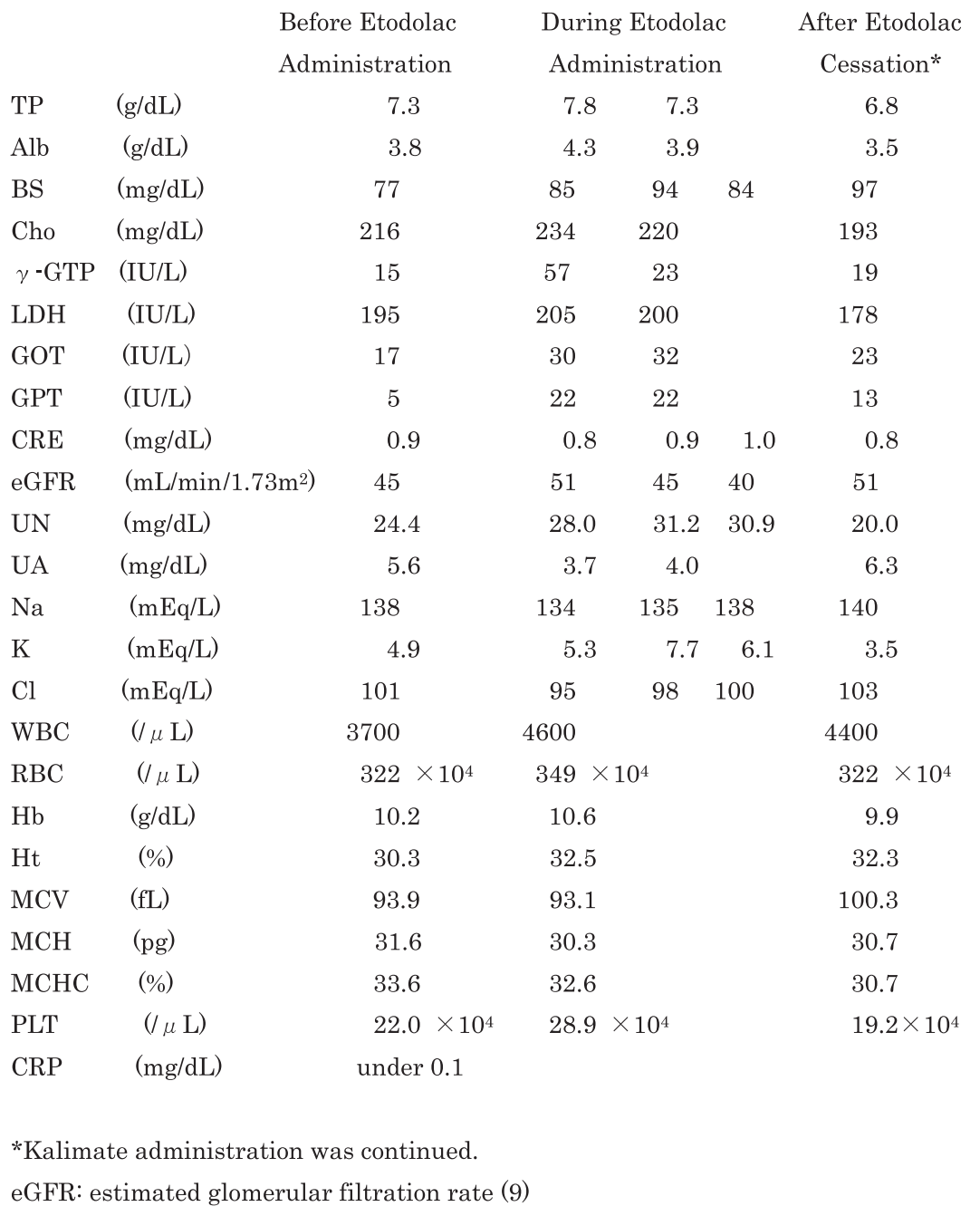

due to gait disturbance and bedridden state, caused by bilateral osteoarthritis of the hips and knees. Her family history was not contributory. She had no history of hypertension. On admission, she had a normal sleep pattern and good appetite with daily calorie intake of $1,200 \mathrm{kcal}$. Dietary salt amount was below approximately $7 \mathrm{~g}$ per day, but it was maintained above approximately $4 \mathrm{~g}$ per day. She had a normal nutritional state with a height of $142 \mathrm{~cm}$ and $40 \mathrm{~kg}$ body weight (body mass index, BMI: $20 \mathrm{~kg} / \mathrm{m}^{2}$ ). Her pulse rate was 50 to $60 / \mathrm{min}$ and regular and her blood pressure was $125 / 68 \mathrm{mmHg}$. There were no abnormal findings on head, neck, chest and abdominal examinations, and her extremities showed no edema. There were no abnormal findings on electrocardiogram (ECG) recordings, including P-R interval, and on a chest X-ray film. No distinct abnormalities were found in the results of blood chemistry, including serum potassium levels, although the serum creatinine level was slightly elevated $(0.9 \mathrm{mg} / \mathrm{dL}$, Table 1$)$. The estimated glomerular filtration rate (eGFR) (9) was moderately decreased $\left(45 \mathrm{~mL} / \mathrm{min} / 1.73 \mathrm{~m}^{2}\right.$, Table 1$)$, but there were no abnormalities in the results of urinalysis. The peripheral blood counts revealed normochromic and normocytic anemia, suggesting simple secondary anemia, as frequently observed in chronically ill patients (Table 1).

Approximately 2 years after admission, she was prescribed NSAID with selective cyclooxygenase type 2 (COX 2) enzyme inhibition (etodolac), $400 \mathrm{mg}$, orally twice daily to relieve arthritic pain in her hip and knee. There were no other prescribed medications, including potassium sparing diuretics, angiotensin-converting enzyme (ACE) inhibitors and angiotensin receptor blockers (ARB), although she was administered non-specific stomatics.

Approximately 3 months after the initiation of etodolac therapy, she complained of dizziness together with nausea without any occasion, although she had no incidence of vomiting. Her consciousness was alert, and there were no abnormal findings, except for the aging brain, on computed tomography (CT) of the brain. Dizziness was improved by administration of betahistine mesilate (merislon). Her appetite was normal. Etodolac administration was still continued, and after a week, she complained again of dizziness and nausea with a slight elevation of serum potassium level (5.3 $\mathrm{mEq} / \mathrm{L}$, Table 1 and Fig. 1).

After approximately 10 hours, marked elevation of serum potassium level $(7.7 \mathrm{mEq} / \mathrm{L}$, Table 1 and Fig. 1) together with bradycardia (heart rate: 30/min) was observed, and 


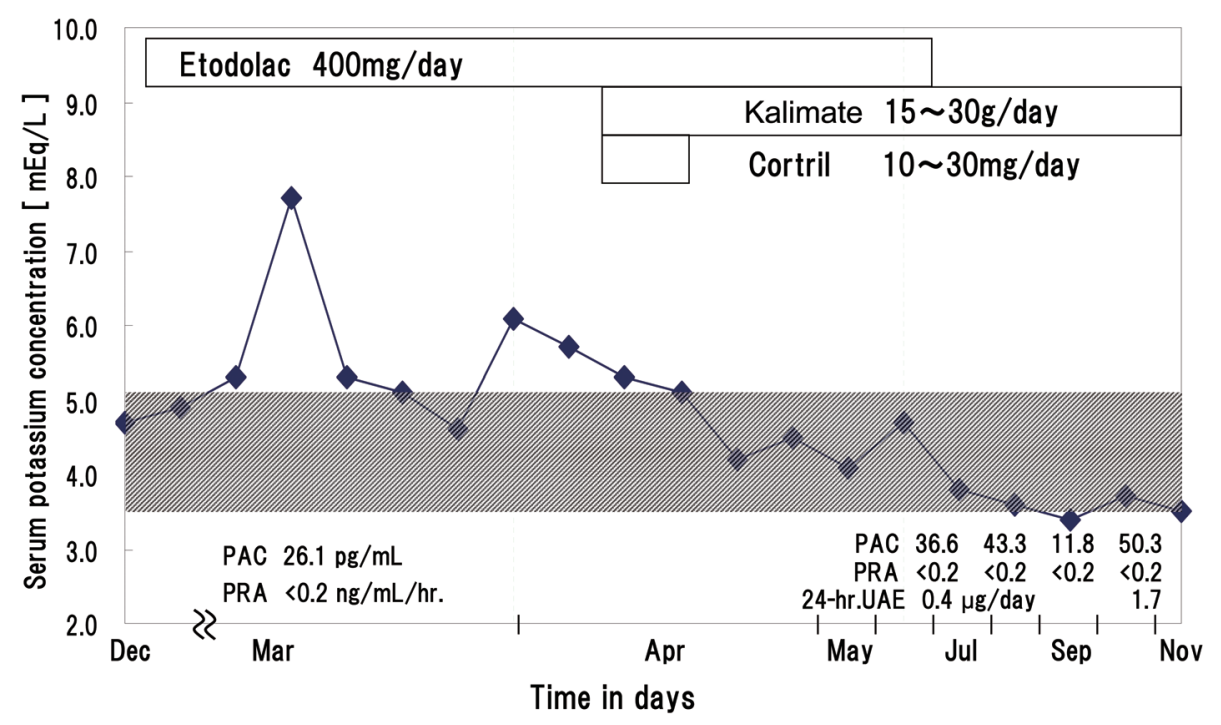

Figure 1. Changes of serum potassium levels. The shadded area indicates the normal range of serum potassium levels. PAC: plasma aldosterone concentration, PRA: plasma renin activity, 24-h UAE: 24-hour urine aldosterone excretion

$\mathrm{HR}: 30 / \mathrm{min}$

$\mathrm{K}: 7.7 \mathrm{mEq} / \mathrm{L}$

(A)

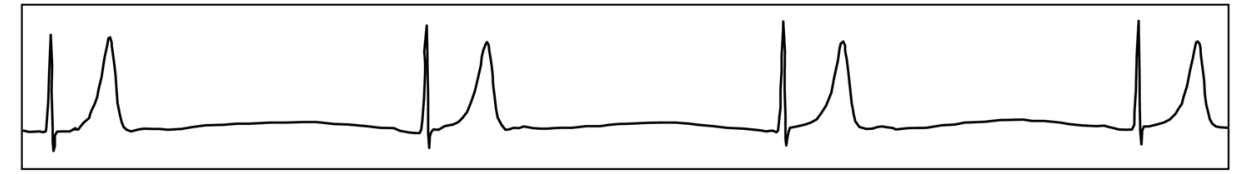

$\mathrm{HR}: 88 / \mathrm{min}$

$\mathrm{K}: 5.3 \mathrm{mEq} / \mathrm{L}$

(B)

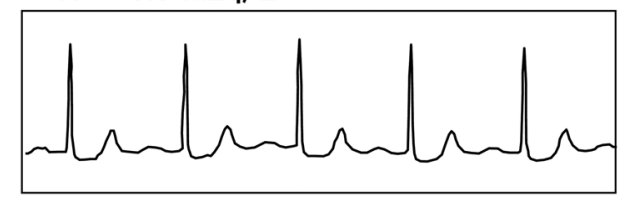

$\mathrm{HR}: 48 / \mathrm{min}$

$\mathrm{K}: 6.1 \mathrm{mEq} / \mathrm{L}$

(C)

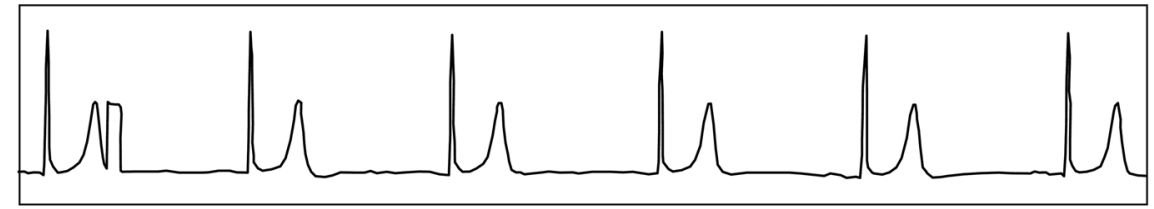

$H R: 53 / \mathrm{min}$

$\mathrm{K}: 4.5 \mathrm{mEq} / \mathrm{L}$

(D)

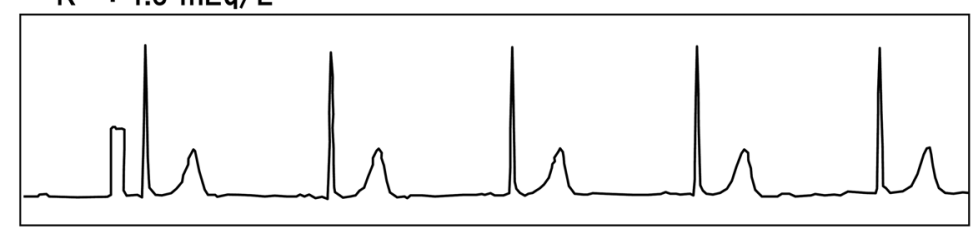

HR : Heart rate

K : Serum K

Figure 2. Association of ECG recordings with serum potassium levels.

bradycardia, a loss of $\mathrm{P}$ wave and peaked $\mathrm{T}$ wave were evident on ECG recordings (Fig. 2A). Her consciousness was alert, and blood pressure was $120 / 74 \mathrm{mmHg}$. The results of blood chemistry, including blood sugar levels, were entirely normal, except for serum creatinine and potassium levels
(Table 1). The values for eGFR were moderately decreased $\left(40-51 \mathrm{~mL} / \mathrm{min} / 1.73 \mathrm{~m}^{2}\right.$, Table 1) (9), and these were relatively similar to that before etodolac administration. The results of urinalysis were also unremarkable. There were no remarkable abnormalities, except for $66.9 \mathrm{mmHg}$ of $\mathrm{PaO}_{2}$ in 
Table 2. Results of Endocrine Function Test

$\begin{array}{llccc} & & \begin{array}{c}\text { During Etodolac } \\ \text { Administration }\end{array} & \begin{array}{c}\text { After Etodolac } \\ \text { Cessation }\end{array} & \text { Normal Ranges } \\ \text { PAC at rest } & (\mathrm{pg} / \mathrm{mL}) & 26.1 & 11.8-50.3 & 52-174 \\ \text { PRA at rest } & (\mathrm{ng} / \mathrm{mL} / \mathrm{hr}) & \text { under } 0.2 & \text { under } 0.2 & 0.3-2.9 \\ 24 \text {-hr UAE } & (\mu \mathrm{g} / \text { day }) & & 0.4-1.7 & 0.6-9.0 \\ \text { ACTH in plasma }(\mathrm{pg} / \mathrm{mL}) & 20.6 & & 7.4-55.7 \\ \text { Cortisol in serum }(\mu \mathrm{g} / \mathrm{dL}) & 11.8 & & 4.8-22.7 \\ \mathrm{TSH}^{(} & (\mu \mathrm{U} / \mathrm{mL}) & & 2.07 & 0.35-3.73 \\ \mathrm{FT}_{4} & (\mathrm{ng} / \mathrm{dL}) & & 1.16 & 0.88-1.81 \\ \mathrm{FT}_{3} & (\mathrm{pg} / \mathrm{mL}) & & 2.2 & 2.2-4.1\end{array}$

PAC: plasma aldosterone concentration, PRA: plasma renin activity, 24-hr UAE: 24-hour urine aldosterone excretion

Table 3. Summary of Laboratory and Endocrinologic Findings in 11 Elderly Patients with Bedridden State due to Central Neurologic Impairments

\begin{tabular}{|c|c|c|c|c|c|}
\hline Case No. & $\begin{array}{c}\mathrm{Na} \\
(\mathrm{mEq} / \mathrm{L})\end{array}$ & $\begin{array}{c}\mathrm{K} \\
(\mathrm{mEq} / \mathrm{L})\end{array}$ & $\begin{array}{c}\text { PRA } \\
(\mathrm{ng} / \mathrm{mL} / \mathrm{hr})\end{array}$ & $\begin{array}{c}\text { PAC } \\
(\mathrm{pg} / \mathrm{mL})\end{array}$ & $\begin{array}{c}\text { 24-hr UAE } \\
(\mu \text { g/day })\end{array}$ \\
\hline $1^{*}$ & 147 & 4.5 & under 0.2 & 75.3 & \\
\hline $2 *$ & 141 & 3.8 & 0.3 & 73.9 & \\
\hline $3^{* *}$ & 138 & 4.1 & 1.8 & 34.0 & \\
\hline $4^{*}$ & 143 & 3.9 & under 0.2 & 60.0 & \\
\hline $5^{*}$ & 143 & 3.7 & under 0.2 & 49.4 & \\
\hline $6^{*}$ & 144 & 4.5 & under 0.2 & 56.3 & \\
\hline $7^{*}$ & 143 & 3.8 & under 0.2 & 58.1 & 1.5 \\
\hline 8 & 135 & 4.5 & 1.0 & 119.3 & 4.4 \\
\hline $9 *$ & 134 & 4.4 & under 0.2 & 36.7 & \\
\hline $10^{*}$ & 140 & 5.2 & under 0.2 & 58.6 & 1.8 \\
\hline $11^{*}$ & 141 & 4.0 & under 0.2 & 41.0 & \\
\hline
\end{tabular}

\footnotetext{
$\mathrm{Na}$ : serum sodium concentration, K: serum potassium concentration, PRA: plasma renin activity, PAC: plasma aldosterone concentration, 24-hr UAE: 24-hour urine aldosterone excretion.

*hyporeninemic hypoaldosteronism with normopotassemia (asymptomatic case)

**ACE inhibitor was prescribed.
}

the results of arterial blood gas analysis $\left(\mathrm{pH} 7.41, \mathrm{PaO}_{2} 66.9\right.$ $\mathrm{mmHg}, \mathrm{PaCO}_{2} 40.8 \mathrm{mmHg}, \mathrm{HCO}_{3}^{-} 25.1 \mathrm{mmol} / \mathrm{L}$ ). Serum potassium level was decreased to almost normal level $(5.3$ $\mathrm{mEq} / \mathrm{L}$, Fig. 1) after intravenous infusion of $20 \mathrm{~mL}$ of calcium gluconate $(7.8 \mathrm{mEq}$ of calcium) and $250 \mathrm{~mL}$ of glucose as a $10 \%$ solution, containing 10 units of regular insulin. Heart rate was $88 / \mathrm{min}$ and peaked $\mathrm{T}$ wave disappeared on ECG recording (Fig. 2B).

She was still administered etodolac, and her serum potassium level again became elevated to $6.1 \mathrm{mEq} / \mathrm{L}$ (Fig. 1), in spite of the restriction of dietary potassium. Blood sugar levels at this time were also within normal limits (Table 1). Thus, increased potassium load and potassium redistribution of intracellular/extracellular space due to insulin deficiency were eliminated in the present patient. ECG recordings revealed heart rate of 48/min and peaked $\mathrm{T}$ wave (Fig. 2C). Serum potassium level and ECG manifestations were re- turned to normal (Fig. 2D and Fig. 1) by administration of calcium polystyrene sulfonate (kalimate), 15-30 g per day, and hydrocortisone (cortril), 10-30 mg per day, exhibiting mimeralocorticoid action as well as glucocorticoid action, although she was still prescribed etodolac. Furthermore, it is noteworthy that, in addition to kalimate administration, $20 \mathrm{~g}$ per day, etodolac cessation resulted in even more distinct diminution of serum potassium values to low normal levels (Fig. 1). Moreover, daily urinary excretions of sodium and potassium were 96 and $123 \mathrm{mEq} /$ day and 9 and $11 \mathrm{mEq} /$ day, respectively, and daily sodium intakes (daily urinary excretion of sodium, mEq/day, / 17) were estimated at 5.6 and 7.2 g/day. Hyperpotassemia was not observed after the discontinuation of etodolac. Thereafter, she left our hospital, and the data on serum potassium levels were not available, following cessation of kalimate and etodolac.

Table 2 shows results of endocrinologic function tests in 
the present patient. Thyroid function was normal, and the basal morning plasma ACTH and serum cortisol levels were within normal limits. On the other hand, it was remarkable that PRA was suppressed (under $0.2 \mathrm{ng} / \mathrm{mL} / \mathrm{hr}$, Fig. 1 and Table 2) and PAC was markedly decreased (11.8-50.3 pg/ mL, Fig. 1 and Table 2) throughout the entire period of the present study. Particularly, it was noted that 24-hour urine aldosterone excretion (24-hr UAE) as well as PRA and PAC were still diminished, though etodolac was discontinued (Fig. 1 and Table 2). PRA and PAC secretions were not stimulated by the sitting position for about 30 minutes.

Moreover, determinations of PRA and PAC were made in 11 patients ( 3 men and 8 women; age 66-100 years; mean, 88 years), selected randomly from 72 bedridden elderly patients (10 men and 62 women; age 66-103 years; mean, 88 years) in our hospital. Their sodium and potassium levels in serum were within the normal limits. They had incidences of cerebral infarction, cerebral bleeding or Parkinson's disease over 2 years before admission. Although they needed the care for decline of ADL, there were no systemic changes suggesting alteration of the "steady state". The dietary salt amounts in these patients were maintained at least above approximately $4 \mathrm{~g}$ per day, suggesting that they had no chronic salt depletion. Twenty-four-hour sodium, potassium and aldosterone excretions were also measured in 3 patients.

As shown in Table 3, serum sodium and potassium levels were within the normal ranges in all 11 patients. On the other hand, values for PRA were suppressed in 8 patients (under $0.2 \mathrm{ng} / \mathrm{mL} / \mathrm{hr}$, normal range; $0.3-2.9 \mathrm{ng} / \mathrm{mL} / \mathrm{hr}$ ) and 1 of the remaining 3 patients had low PRA $(0.3 \mathrm{ng} / \mathrm{mL} / \mathrm{hr})$. These 9 patients with decreased PRA showed low normal or low PAC (36.7-75.3 pg/mL, normal range; $52-172 \mathrm{pg} / \mathrm{mL}$, Table 3), and values for 24-hr UAE, determined in 2 patients, were also low normal (1.5 and $1.8 \mu \mathrm{g} / \mathrm{day}$, normal range; $0.8-9.0 \mu \mathrm{g} /$ day, Table 3$)$. PRA in 1 of other 2 patients was $1.8 \mathrm{ng} / \mathrm{mL} / \mathrm{hr}$, whereas PAC was markedly diminished (34.0 pg/mL, No. 3 in Table 3). This patient was prescribed ACE inhibitor. PRA, PAC and 24-hr UAE in the remaining 1 patient were entirely normal (No.8 in Table 3). Daily urinary excretions of sodium and potassium, determined in 3 patients, were 69, 99 and $116 \mathrm{mEq} /$ day and 20, 20 and 29 $\mathrm{mEq} /$ day, respectively, and estimated daily sodium intakes were 4.1, 5.8 and $6.8 \mathrm{~g} / \mathrm{day}$. Thus, hyporeninemic hypoaldosteronism with normopotassemia (asymptomatic case) was observed in 9 of the 11 patients (Table 3).

Venous blood samples were drawn from all patients before breakfast after an overnight fast. PRA, PAC and 24-hr UAE were assayed using commercially available kits in ikagaku Medical Science, Kyoto, Japan.

\section{Discussion}

Advanced age is known to lead to the impaired release of renin with subsequent hypoaldosteronism (10). Moreover, it has been previously reported that the posture of the subject is a regulating factor for renin and aldosterone secretions as a volume dependent stimulus (4). As may be anticipated by these findings $(4,10)$, the incidence of hyporeninemic hypoaldosteronism might be further increased in bedridden elderly patients. This was consistent with the present findings that 9 of 11 bedridden elderly patients showed hyporeninemic hypoaldosteronism. It has been believed that aldosterone deficiency does not cause hyperpotassemia unless the patient is "salt deprived" (dietary salt amount below $4 \mathrm{~g}$ per day) (11). Moreover, hyperpotassemia induced by hypoaldosteronism was aggravated by sodium restriction (3). The daily salt intake in the present bedridden patients with hyporeninemic hypoaldosteronism was maintained above approximately $4 \mathrm{~g}$, showing that they had no chronic salt depletion. This was supported by the results that daily salt intakes in 3 patients, estimated from daily urinary excretion of sodium, were $4.1,5.8$ and $6.8 \mathrm{~g} / \mathrm{day}$. Thus, their serum potassium levels were entirely normal, in spite of hyporeninemic hypoaldosteronism. Thus, it was considered sufficient from the present findings that asymptomatic hypoaldosteronism associated with suppressed renin activity was not infrequently observed in bedridden elderly patients.

In the present paper, an 85-year-old bedridden woman showed diminished PRA and PAC, and her adrenoglucocorticoid function was normal. It was remarkable that she had hyperpotassemia, suggesting selective hypoaldosteronism associated with low renin activity. Her dietary salt intake was maintained above approximately $4 \mathrm{~g}$ per day throughout the entire period of the present study, and, in fact, her daily salt intakes, estimated from daily urinary sodium excretions, were 5.6 and $7.2 \mathrm{~g} /$ day. Thus, as discussed below, additional factors to induce hyperpotassemia may be operative in the present patient.

It was noted that the present patient was prescribed NSAID, selective COX-2 inhibitor (etodolac), to relieve arthritic pain of hip and knee. Since COX-2 inhibitor is albumin-bound, hypoalbuminemia itself may conceivably permit non-protein-bound free COX-2 inhibitor to cause the side-effect. However, the serum albumin concentration was normal (3.8-4.3 g/dL) in the present patient. It has been described in previous reports $(7,8,10,12-19)$ that NSAID suppresses renin secretion through the inhibition of renal prostaglandin $\left(\mathrm{PGE}_{2}\right.$ and $\left.\mathrm{PGI}_{2}\right)$ synthesis by $\mathrm{COX}-1$ and COX-2 inhibition. PAC is also diminished in parallel with renin suppression. Moreover, $\mathrm{PGE}_{2}$ modulates the function of high-conductance potassium channels, which helps facilitate potassium excretion in the distal tubule $(8,15,16,18,20)$. The impairment of this direct effect of $\mathrm{PGE}_{2}$ on potassium excretion might also play a role in reduced potassium excretion, observed with NSAID administration $(8,15,16,18)$. In addition, NSAID causes vasoconstriction, which impairs salt and water delivery to the distal tubule, further reducing renal potassium excretion (8). Reversible acute renal failure and hyperpotassemia were also caused by administration of selective COX-2 inhibitor (21), which was prescribed in the present patient. Thus, the use of NSAID's, selective COX-2 inhibitor and nonselective COX- 
1/COX-2 inhibitor, might result in hyporeninemic hypoaldosteronim with impaired potassium homeostasis.

It was expected that, because of bedridden state due to gait disturbance, the present elderly patient might have shown suppressed PRA and PAC prior to etodolac administration, although the data on PRA and PAC were not available before NSAID administration. This is supported by the fact that PRA, PAC and 24-hr UAE were still diminished after NSAID cessation in the present patient. Moreover, it was noticeable that, despite hyporeninemic hypoaldosteronism, a distinct diminution of serum potassium value to low normal level was observed after etodolac cessation, in addition to kalimate administration.

In the present patient, the value for eGFR was $45 \mathrm{~mL} / \mathrm{min} /$ $1.73 \mathrm{~m}^{2}$ before etodolac administration, suggesting "moderate" chronic kidney disease (CKD, stage III) (9), and the values were nearly unchanged $\left(40-51 \mathrm{~mL} / \mathrm{min} / 1.73 \mathrm{~m}^{2}\right)$ throughout the entire study period, irrespective of whether hyperpotassemia existed or not. Therefore, NSAID may intensify the risk of hyperpotassemia in such patients with renal impairment.

In the present patient, marked hyperpotassemia was found for the first time about 3 months after the initiation of etodolac therapy. Moreover, her potassium level in serum was markedly elevated from 5.3 to $7.7 \mathrm{mEq} / \mathrm{L}$ for a period of approximately 10 hours. An elevation of serum potassium level was also observed, despite restriction of dietary potassium amount. Hyperpotassemia induced by long-term administration of indometacin has been previously reported in a patient with renal impairment (7) and they observed a marked elevation of serum potassium level on numerous occasions throughout the entire period the patient received indometha- cin. This clinical course was similar to that observed in the present patient. Although additional factors to cause a sharp elevation of serum potassium level could not be found in present patient, the present observation was compatible with the previous finding (19) that the velocity of the development of hyperpotassemia was correlated with the extent of hyperpotassemia.

Finally, consideration regarding bradycardia observed in the present case is necessary. Patients with hyperpotassemia and syncopal attacks due to complete heart block have been previously described $(1,2)$, and they had selective hypoaldosteronism. Moreover, in these patients, hyperpotassemia and the recurrence of syncopal attacks were not observed, following treatment with 9-alpha-fluorohydrocortisone, a potent electrolyte-active steroid $(1,2)$. However, the association of hypoaldosteronism with complete heart block was still uncertain in these cases $(1,2)$. Prolongation of the P-R interval, followed by a loss of $\mathrm{P}$ wave with peaked $\mathrm{T}$ wave, on ECG recordings become evident, when the serum potassium level exceeded approximately $6.5 \mathrm{mEq} / \mathrm{L}$ (22). Serum potassium concentrations in the present patient were 6.1 and $7.7 \mathrm{mEq} / \mathrm{L}$ and her ECG manifestations were compatible with the serum potassium level. Therefore, it was considered reasonable that the clinical pictures in the present patient as well as in the previous patients $(1,2)$ may be due to the effect of hyperpotassemia secondary to hypoaldosteronism.

In conclusion, the abnormalities may be exacerbated to cause hyperpotassemia, when NSAID is used in the elderly patients with preexisting asymptomatic hyporeninemic hypoaldosteronism, and particularly when accompanied by renal impairment.

\section{References}

1. Hudson JB, Chobanian A, Relman AS. Hypoaldosteronism: a clinical study of a patient with an isolated adrenal miniralocorticoid deficiency, resulting in hyperkalemia and Stokes-Adams attacks. N Engl J Med 257: 529-536, 1957.

2. Lambrew CT, Carver ST, Peterson RE, Horwith M. Hypoaldosteroism as a cause of hyperkalemia and syncopal attacks in a patient with complete heart block. Am J Med 31: 81-85, 1961.

3. Perez G, Siegel L, Schreiner GE. Selective hypoaldosteronism with hyperkalemia. Ann Intern Med 76: 757-763, 1972.

4. Michelis MF, Murdaugh HV. Selective hypoaldosteronism. An editorial revisited after 15 years. Am J Med 59: 1-5, 1975.

5. Mizuno K, Yamamoto S, Lands WEM. Effect of non-steroidal anti-inflammatory drugs on fatty acid cyclooxygenase and prostaglandin hydroperioxidase activities. Prostaglandins 23: 743757, 1982.

6. Kulmarz RJ. Topography of prostaglandin H synthase. Antiinflammatory agents and the protease-sensitve arginine 253 region. J Biol Chem 263: 14136-14144, 1989.

7. Tan SY, Shapiro R, Franco R, et al. Indomethacin-induced prostaglandin inhibition with hyperkalemia. A reversible cause of hyporeninemic hypoaldosteronism. Ann Intern Med 90: 783-785, 1979.

8. Perazella MA. Drug-induced hyperkalemia: Old culprits and new offender. Am J Med 109: 307-314, 2000.

9. Japan Kidney Society, Ed. Clinical Practice Guidebook for Diag- nosis and Treatment of Chronic Kidney Disease 2009. Tokyo Igakusha, Tokyo, 2009: 33-40 (in Japanese).

10. Palmer BF. Managing hyperkalemia caused by inhibitors of reninangiotensin-aldosterone system. N Engl J Med 351: 585-592, 2004.

11. Loriaux DL. Adrenal cortex. In: Cecil Textbook of Medicine. 20th ed. Bennet JC, Plum F, Eds. W.B. Saunders Company, Philadelphia, 1996: 1245-1252.

12. Romero JC, Dunlap CL, Strong CG. The effect of indomethacin and other anti-inflammatory drugs on the renin-angiotensin system. J Clin Invest 58: 282-288, 1976.

13. Speckart P, Zia P, Zipser R, Horton R. The effect of sodium restriction and prostaglandin inhibition on the renin-angiotensin system in man. J Clin Endocrinol Metab 44: 832-837, 1977.

14. Garelia S, Matarese RA. Renal effect of prostaglandins and clinical adverse effects of nonsteroidal anti-inflammatory agents. Medicine 63: 165-181, 1984.

15. Ponce SP, Jennings AE, Madias NE, Harrington JT. Drug-induced hyperkalemia. Medicine 64: 357-370, 1985.

16. Schlondorff D. Renal complications of nonsteroidal anti-inflammatory drugs. Kidney International 44: 643-653, 1993.

17. Weissmann G. NSAID's: Aspirin and aspirin-like drugs. In: Cecil Textbook of Medicine. 20th ed. Bennet JC, Plum F, Eds. W.B. Saunders Company, Philadelphia, 1996: 111-115.

18. Evans KJ, Greenberg A. Hyperkalemia: A review. J Intensive Care 
Med 20: 272-290, 2005.

19. Indermitte $J$, Burkolter $S$, Drewe J, et al. Risk factors associated with a high velocity of the development of hyperkalemia in hospitalised patients. Drug Safety 30: 71-80, 2007.

20. Ling BN, Webster CL, Eaton DC. Eicosanoids modulate apical $\mathrm{Ca}^{2+}$-dependent $\mathrm{K}^{+}$channels in cultured rabbit principal cells. Am J
Physiol 263: F116-F126, 1992.

21. Perazella MA, Eras J. Are selective COX-2 inhibitors nephrotoxic? Am J Kidney Dis 35: 937-940, 2000.

22. Kokko JP. Disturbances in potassium balance. In: Cecil Textbook of Medicine. 20th ed. Bennet JC, Plum F, Eds. W.B. Saunders Company, Philadelphia, 1996: 538-543.

\footnotetext{
(C) 2010 The Japanese Society of Internal Medicine http://www.naika.or.jp/imindex.html
} 